\title{
Desarrollo de un sistema de detección de anticuerpos contra COVID-19 basado en el principio de inmunocromatografía
}

\author{
Ortiz, Gastón ${ }^{1,2}$; Sebastián F. Cavalitto ${ }^{1}$ \\ ${ }^{1}$ CINDEFI (CONICET La Plata - UNLP); ${ }^{2}$ UNaHur; ${ }^{3}$ cavalitto@quimica.unlp.edu.ar
}

Resumen. Con la llegada del COVID-19 a la Argentina se evidencio la falta de herramientas de origen local que permitieran mitigar los efectos de la pandemia desde el punto de vista epidemiológico. Una de estas herramientas claves para dicho propósito, contempla el uso de métodos de diagnóstico rápidos y eficientes. Dentro de cuales, el más versátil, desde un punto de vista de su relación costo beneficio, lo constituyen los llamados test serológicos rápidos. Este tipo de métodos, permiten realizar estudios poblacionales a gran escala con la finalidad de hallar individuos infectados y trazar redes de contactos estrechos, permitiendo desde el punto de vista epidemiológico realizar mapeo y segregación de áreas contemplando métricas como incidencia de la enfermedad e inmunidad poblacional adquirida. El principio de este tipo de herramienta se basa en la detección de anticuerpos en sangre mediante un principio inmunocromatográfico y detección visual. Este sistema, debido a su baja complejidad y bajo costo de sus componentes permite su implementación sin la necesidad de una infraestructura hospitalaria o laboratorio. Para la realización de la prueba diagnóstica se requiere de una gota de sangre digital del individuo a testear y de la aplicación de la misma en el dispositivo, posteriormente mediante el agregado de una gota del reactivo cromatográfico se puede evidenciar la aparición de color en una o dos líneas de testeo, las cuales indicaran si la persona analizada posee o no anticuerpos contra el COVID-19. Si el resultado es positivo, indicativo de está o ha estado en contacto con el virus. Por ello, este tipo de test permite al personal sanitario tomar decisiones inmediatas acerca de la situación de una persona o grupo de personas positivas.

Palabras clave: tiras reactivas; análisis serológico; Farmacoop.

Recibido: 06/10/2020 Aceptado: 09/10/2020

DOI: https://doi.org/10.24215/26838559e016 


\section{Development of a detection system for antibodies against COVID-19 based on the principle of immunochromatography}

Abstract. With the arrival of COVID-19 to Argentina, the lack of tools of local origin that would mitigate the effects of the pandemic from the epidemiological point of view was evidenced. One of these tools for this purpose contemplates the use of quick and efficient diagnostic methods. Among which, the most versatile, from a cost-benefit point of view, are the socalled rapid serological tests. This type of method allows large-scale population studies to be carried out in order to find infected individuals and draw close contact networks, allowing from an epidemiological point of view to carry out mapping and segregation of areas, considering metrics such as incidence of the disease and acquired population immunity. The principle of this type of tool is based on the detection of antibodies in blood using an immunochromatographic principle and visual detection. This system, due to its low complexity and low cost of its components, allows its implementation without the need for a hospital or laboratory infrastructure. To carry out the diagnostic test, a drop of blood from the individual to be tested is required and its application in the device, subsequently by adding a drop of the chromatographic reagent, the appearance of color in one or more two test lines, which will indicate whether or not the person analyzed has antibodies against COVID 19. If the result is positive, indicative of being or has been in contact with the virus. Therefore, this type of test allows healthcare personnel to make immediate decisions about the situation of a positive person or group of people.

Key words: lateral flow; point of care, local development.

\section{Novedad u originalidad local en el conocimiento}

Al momento de la aparición de los primeros casos de COVID-19 en el país, la Argentina no poseía desarrollos locales de sistemas de detección de la enfermedad, tanto en forma molecular (detección del virus por RT-PCR) como serológica (por 
detección de anticuerpos anti COVID). Fue en ese momento que desde el grupo de Biotecnología de enzimas del CINDEFI, instituto de doble dependencia (CONICETUNLP) situado dentro de la Facultad de Ciencias Exactas, decidimos comenzar con el desarrollo de un sistema de detección de anticuerpos (IgG e IgM) mediante el sistema de inmunocromatografía (Lateral Flow). Desde la base de nuestro conocimiento de los bioprocesos y de la producción de proteínas recombinantes, con la finalidad de tener cantidad suficiente de la proteína sin la necesidad de manipular al virus se procedió con el clonado y expresión de una de las proteínas virales (Proteína, Np). El gen de dicha proteína fue clonado y producido de forma recombinante en la bacteria Escherichia coli. Esta proteína es clave para el desarrollo ya que la misma le da especificidad al sistema, siendo la molécula (antígeno) que puede ser reconocida por los anticuerpos de la persona que está o estuvo infectada por el COVID-19. Una vez obtuvimos la proteína purificada comenzamos con la etapa del desarrollo que resulto ser la más desafiante para nuestro grupo de investigación. Esta fue seleccionar las condiciones de testeo que permitiesen obtener un test que fuera sensible y especifico (requerimientos fundamentales para cualquier sistema testeo por sondeo). Esta parte resultó compleja, debido a los plazos con los que contábamos para el desarrollo, la falta de experiencia en sistemas inmunocromatográficos y falta completa de insumos locales para su realización. 


\section{Grado de relevancia}

Tener un sistema nacional de detección serológica de COVID-19 permite independizarse de los vaivenes del mercado mundial y en el contexto de una pandemia, donde la mayoría de los países poseen las mismas necesidades diagnósticas que nuestro país. Por ello, dependiendo de la escala a la que el sistema pueda ser producido nuestro producto puede reemplazar parcial o totalmente a los productos importados y en el mejor de los casos ser exportado teniendo en ese caso el beneficio adicional de ser un generador de divisas genuinas para el país. El desarrollo de este sistema detección por el ámbito académico público (CONICETUUNN) en colaboración con el sector productivo Bamboo Biotech SAS y Alimentos Proteicos SA quienes financiaron el presente desarrollo. Por ello, este proyecto evidencia esquema asociativo público-privado, donde actúan sinérgicamente el conocimiento bien direccionado de un grupo académico y los intereses del sector privado, en post de brindar bienes y servicios a la sociedad. El desarrollo, fue ideado y ejecutado desde el comienzo con la finalidad de su transferencia al sector productivo, siendo el adoptante del desarrollo la cooperativa farmacéutica Farmacoop Lta (cooperativa farmacéutica recuperada por sus empleados luego de la quiebra de Roux Ocefa), por tal motivo este proyecto además del aporte directo a la salud pública, brinda un beneficio directo en la generación de nuevos puestos de trabajo genuinos y de calidad. 
Innovación y Desarrollo Tecnológico y Social (2020) 2 (2): 51-64

\section{Grado de pertinencia}

La Argentina al igual que él resto de los países afectados por la pandemia de COVID19 necesita de herramientas que le permitan manejar a la evolución epidemiológica de la forma más racional posible. De todas las herramientas necesarias, los métodos de diagnóstico constituyen la primera línea de batalla para mitigar los efectos de la propagación del virus y actuar en consecuencia para su contención. Dentro de este contexto, el desarrollo generado por nuestro grupo de investigación da una respuesta tangible para dicha demanda. brindando así, tecnología de vanguardia e insumos para la manufactura de test serológicos de calidad que serán empleados con los fines detallados anteriormente. Es importante destacar que, desde la óptica innovadora nuestro desarrollo resulta altamente pertinente puesto que en la actualidad no existente elaboración u desarrollo de test serológicos rápidos para COVID-19 en Argentina.

\section{Grado de demanda}

Este desarrollo nació directamente de una demanda existente. El mercado potencial en la Argentina para este tipo de test de diagnóstico es de varios millones. Aun suponiendo que parte del mercado seguirá siendo cubierto por empresas extranjeras, la posibilidad de ventas de un test de producción nacional de buena calidad resulta competitiva desde el punto de vista comercial, dado que los tiempos de respuesta y de cercanía con los clientes. Este potencial mercado de ventas y el 
contexto comercial nos llevó a plantear el desarrollo tecnológico a las empresas Bamboo Biotech SAS y Alimentos Proteicos SA, quienes evaluaron la propuesta y aceptaron financiar el proyecto. Luego, durante el desarrollo del proyecto comenzamos a evaluar potenciales adoptantes de la tecnología, allí surgió la posibilidad de que él proyecto tenga como adoptante la cooperativa Farmacoop Lta y de este modo que el proyecto adquiera una fuerte connotación desde la óptica social y productiva. Tras su incorporación al proyecto, la cooperativa farmacéutica comenzó con la adecuación de sus instalaciones para cumplir con los requerimientos regulatorios de ANMAT para la elaboración de productos de diagnóstico in-vitro. Por su parte Alimentos Proteicos SA financió y gestiono la compra del equipamiento e insumos requerido para la producción de los test, mientras que Bamboo Biotech SAS se encargó de financiar el desarrollo tecnológico. Desde el punto de vista del desarrollo, el mismo ya se encuentra finalizado y la transferencia del mismo ya fue realizada a Farmacoop Lta. Por ello, solo queda esperar el impacto y grado de éxito que la tecnología aquí generada pueda alcanzar. Finalmente, podemos mencionar este desarrollo ha sido declarado de interés Nacional por la Honorable Cámara de Diputados de la Nación (ver video).

\section{Desarrollo del producto}

Los sistemas de inmunocromatográfica se basan en la interacción dinámica entre uno antígenos inmovilizados en la superficie de un soporte sólido (papel de 
nitrocelulosa) que interacciona con las inmunoglobulinas de la muestra presentes en la fase móvil (líquida) las cuales previamente interaccionan con anticuerpo (Ac) anti-especie conjugados a un colorante (Oro coloidal). Brevemente, cuando la muestra es colocada en el dispositivo las inmunoglobulinas (IgG o IgM humana) interaccionan con el Ac conjugado y las mismas son de esta forma etiquetadas o coloreadas. Luego, este complejo coloreado difunde por el soporte sólido (nitrocelulosa) hasta que encuentra la línea de antígeno inmovilizado, aquí sí en el complejo (Ac-IgG o Ac-IgM) se encuentran presentes anticuerpos que reconocen el antígeno Np entonces el complejo será retenido mostrando una línea de coloración rosada o roja (muestra positiva para COVID-19) caso contrario si el complejo no presenta anticuerpos anti-Np continuará difundiendo hasta encontrarse con la línea control. De esta forma, si la muestra no posee Ac contra COVID-19, se hará visible una línea coloreada mientras que, si hubiera Ac específicos, se harán visibles dos líneas coloreadas.

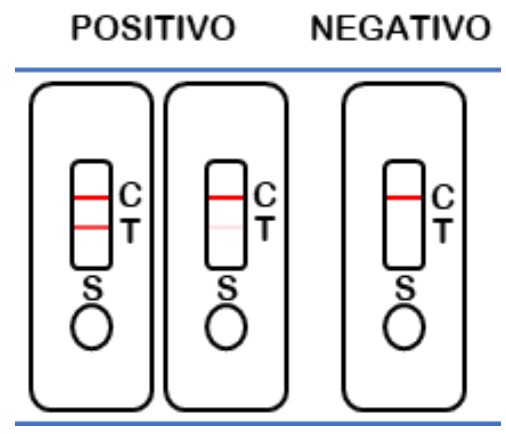

Figura 1: Resultados esperados de un sistema de detección de anticuerpos por lateral flow.

Figure 1: Expected results of a lateral flow antibody detection system. 
Este desarrollo comenzó como una inquietud desde nuestra posición de investigadores por brindar algún tipo de respuesta sanitaria que le permitiese a nuestro país contar con herramientas que permitiesen enfrentar el inminente a avance de la hacía nuestro continente y en particular en nuestro país. Por ello, comenzamos a principios de marzo a gestar la idea proyecto mediante un análisis de factibilidad técnica y comercial, a partir de ese momento elaboramos un plan de negocios y asumimos el riesgo del prototipado financiándonos con recursos propios. En primera instancia, como no se sabía demasiado de este nuevo corona virus y que proteínas podían ser las candidatas para desarrollar un test de diagnóstico, nos basamos en publicaciones científicas previas de SASR y MERS y en el estudio bioinformático de regiones inmunodominantes de proteínas candidatas del nuevo corona virus SARS-CoV2. A partir de estos estudios, se diseñaron dos genes sintéticos uno de ellos codificante para la expresión de la proteína candidata la proteína Np (la proteína que sirve de estructura para el ácido nucleico del virus) y una proteína quimera para formada por la proteína Np dominios de la proteína Sp (la proteína de las espículas del virus). Posteriormente, a mediados del mes Abril cuando los genes llegaron a nuestro laboratorio comenzamos con el clonado y la obtención de los clones productores de E coli. Rápidamente, realizamos la selección de los clones en micro-cultivos y evaluamos la expresión de las proteínas la cual resulto ser satisfactoria. Sin embargo, en este momento del desarrollo no teníamos idea si los antígenos que producía E coli podían ser funcionales, y para ello debíamos 
aumentar de escala los cultivos y obtener la proteína de forma pura para evaluar su desempeño como antígeno. Entonces continuamos con el escalado, el cual fue particularmente complejo debido a que las estructuras de estas proteínas eran complejas y se mostraban inestable y poco solubles. Esta parte del desarrollo exigió de mucho tiempo y conocimiento previo de cultivos, que afortunadamente poseíamos dado que nuestro laboratorio se especializa en el estudio de procesos fermentativos y producción de proteínas recombinantes en diferentes sistemas de expresión. Por ello, en base a nuestro conocimiento previo pudimos sortear exitosamente este cuello de botella y hallar las condiciones de cultivo y expresión que permitieran obtener suficiente cantidad de proteína soluble como para continuar con los pasos siguientes del desarrollo. Una vez asegurada la producción de la proteína, se evaluó la funcionalidad de la misma mediante ensayos serológicos del tipo de ELISA, en este paso se buscó poder discriminar entre sueros positivos (de personas con PCR positiva) y negativas (los miembros del equipo de trabajo) y los resultados obtenidos de este análisis resultaron ser prometedores. Lo logrado hasta este momento, nos motivo a la búsqueda de recursos económicos para llevar el proyecto de la etapa prototipo a etapa de desarrollo. En primera instancia, intentamos obtener fondos mediante la presentación de los PICT COVID-19 ofrecidos por la (Agencia de Promoción Científica y Tecnológica) pero lamentablemente no logramos conseguir financiación estatal. No obstante, lejos de desmotivarnos y con la convicción de que el desarrollo era necesario para nuestra 
sociedad, nos aventurarnos en la búsqueda inversores privados quienes vieron en nuestro proyecto un buen potencial técnico y comercial.

Una vez obtenido el fondeo necesario para el desarrollo, nuestro siguiente paso fue avanzar con el desarrollo del sistema inmunocromatográfico en sí mismo. El cual consiste de una tira reactiva formada por 5 componentes, un papel adhesivo (soporte mecánico) sobre el cual se montan los demás componentes papel de nitrocelulosa (donde se desarrolla la cromatografía/reacción) un papel donde se recibe la muestra (sample pad), un papel donde se dispensan los Ac conjugados (conjugate pad) y finalmente en el extremo opuesto un papel absorbente que sirve para retirar el excedente de la fase móvil (líquido). De cada uno de estos "papeles" los hay con distintas propiedades que le brindan al ensayo mayor o menor sensibilidad y/o especificidad en esta etapa del desarrollo se seleccionó la combinación que diera mejores resultados.

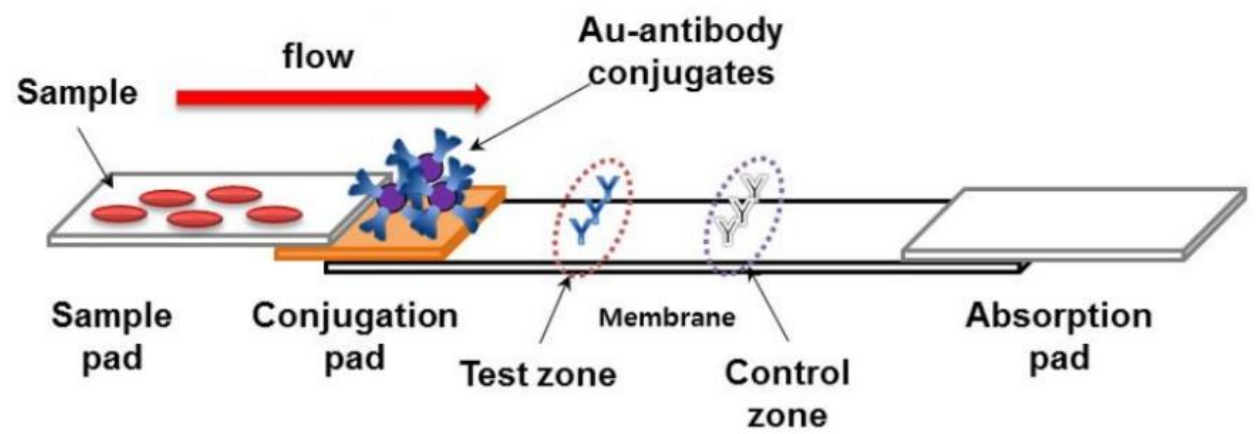

Figura 2. Esquema de la tira reactiva de la detección de anticuerpos por lateral flow Tomado de https://www.creative-diagnostics.com/food-analysis/tag-lateral-flowimmunoassay-30.htm 
Innovación y Desarrollo Tecnológico y Social (2020) 2 (2): 51-64

Figure 2 (previous page). Diagram of the reagent strip for the detection of antibodies by lateral flow. Taken from https://www.creative-diagnostics.com/food-analysis/taglateral-flow-immunoassay-30.htm

Una vez que se seleccionaron los componentes más adecuados para la detección de los Ac anti COVID-19, se procedió a la última etapa del desarrollo. Los Ac suelen tener pegado inespecífico sobre soportes sintéticos, esto conduce a que sueros negativos den resultados positivos (falsos positivos). A fin de evitar este fenómeno, la superficie de la nitrocelulosa debe tratarse con agentes bloqueantes como albúmina sérica bobina y/o caseína, los cuales son inertes a la reacción antígeno/anticuerpo. En la última etapa del desarrollo empleando un diseño estadístico de experimentos (DOE) se seleccionaron la concentración de ambas proteínas de forma tal de maximizar la sensibilidad del sistema (ausencia de falsos negativos) sin que se afecte la especificidad (presencia de falsos positivos). Mientras se optimizaban estas últimas condiciones del sistema, iniciamos dos subproyectos, los cuales resultaron ser muy beneficioso. Un de ellos consistió en el reemplazo de los casettes plásticos donde se introduce la tira reactiva para su uso (originalmente de origen importado) por uno de origen nacional. Como resultado, una industria plástica de la zona del Gran Buenos Aires comenzó a producir un insumo exclusivo para en kit de diagnóstico. 


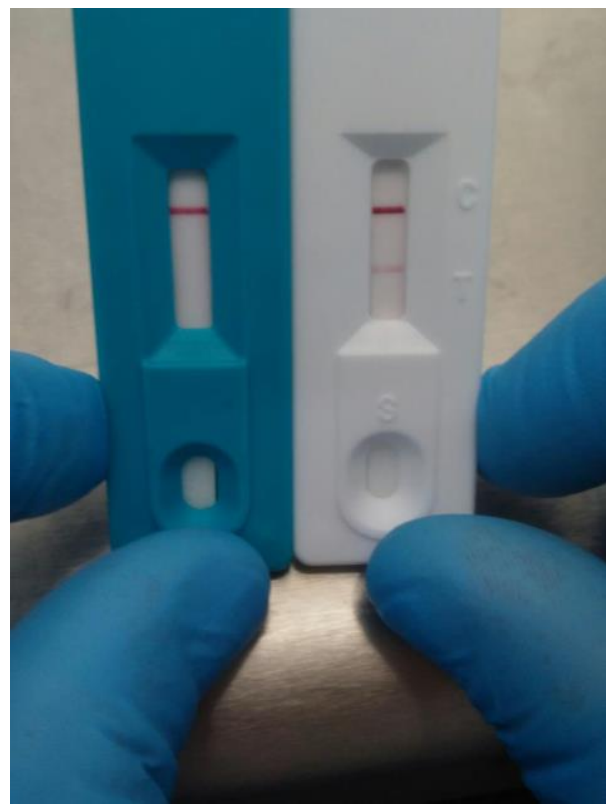

Figura 3. Casettes de plastico desarrollados por una empresa local para nuestro producto. Se realizaron en dos colores para diferenciar el kit para la deteccion de IgG del de IgM.

Figure 3. Plastic cassettes developed by a local company for our product. They were made in two colors to differentiate the kit for the detection of IgG from that of IgM.

Finalmente, también con el fin de reemplazar un insumo importado por uno nacional, nos pusimos en contacto con un grupo del INIFTA (CONICET - UNLP) a fin de que nos desarrollaran nanopartículas de oro empleadas en el conjugado de los Ac. Luego de distintas pruebas, pudimos comprobar que las nanopartículas de diseño local resultaron de mejor calidad que las importadas por lo que fueron incorporadas al desarrollo luego de realizar un convenio con el INIFTA para que ellos las produzcan.

En resumen, como respuesta a una necesidad concreta del País frente a la pandemia, desde un centro de investigación de CONICET y la UNLP y en un lapso de 
seis meses, se realizó un desarrollo tecnológico, mediante una asociación publica privada, comenzando desde una idea para culminar en el registro de un producto ante ANMAT, su producción y su venta.

\section{Información sobre el patentamiento/registro de la innovación o desarrollo}

La tecnología desarrollada durante el proyecto no es patentable ya que se basa en sistemas ya conocidos cuyas patentes (las del lateral flow en particular) caducaron hace ya varios años.

\section{Financiamiento}

Más allá de los gastos de funcionamiento del CINDEFI y los salarios de los investigadores involucrados, el desarrollo no contó con financiamiento estatal, habiendo sido cubierto el desarrollo y compra de equipamiento por la empresa Bamboo Biotech SAS y Alimentos Proteicos SRL.

\section{Agradecimientos}

Agradecemos a nuestros inversores Bamboo Biotech SAS y Alimentos Proteicos SA quienes depositaron su confianza en nosotros y en nuestras capacidades. Queremos agradecer también a todos aquellos, grupos de investigaciones dentro y 


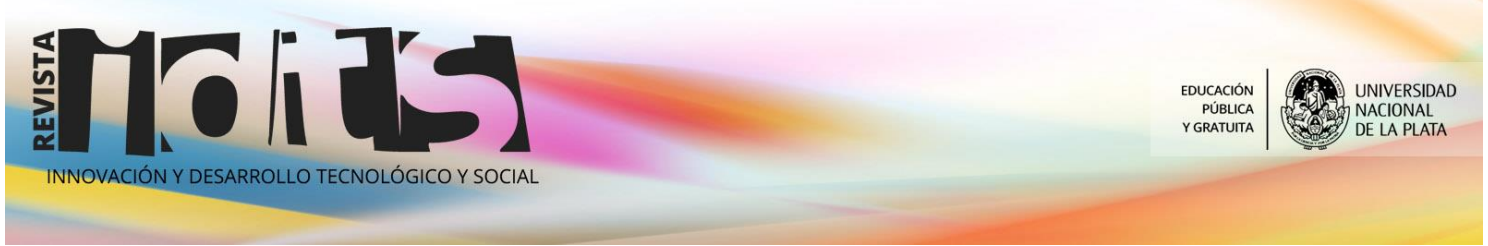

Innovación y Desarrollo Tecnológico y Social (2020) 2 (2): 51-64

fuera del CINDEFI y centros de salud que de una forma desinteresada nos brindaron su apoyo durante la realización de este proyecto.

\section{Referencias bibliográficas}

Jhong-LinWu, Wen-PinTseng, Chien-HaoLin, Tai-FenLee, Ming-YiChung, ChienHuaHuang, Shey-Ying Chen, Po-RenHsueh, Shyr-ChyrChen. (2020). Four point-ofcare lateral flow immunoassays for diagnosis of COVID-19 and for assessing dynamics of antibody responses to SARS-CoV-2. Journal of Infection, 81 (3), 435-442. https://doi.org/10.1016/j.jinf.2020.06.023 